\title{
The Situation of Performance Art in Iran, Past and Present
}

\author{
Parisa Shad Ghazvini \\ Alzahra University, Tehran, Iran
}

\begin{abstract}
Performance art in every region and country depends mainly on rules, customs, and beliefs of that particular society hence; this art enjoys diversity with respect to its forms and contents. In contemporary Iran, with the emergence of new artistic movements, performance art incorporated more academic and enlighten aspects. New mass media and modern visual medium such as light, sound, moving, and changing images, video displays as well as application of new signs and symbols are some of the special characteristics of the contemporary performance art in Iran. Moreover, the performance art in Iran is not merely related to the contemporary era rather it encompasses a large number of traditional representations that have been prevalent among common people with much meaningful rules. Its popularity among common people is also a conceptual art which conveys a content-based meaning in a more dramatic sense. For centuries, the tradition of performance art in Iran can be observed in the rules of Ta'aziehkhani (quite singing or passion play), Shamayelgardani (icon handling), Ru-howzi (performance on pool platform), Marekegiri (mono drama), Qhashoqhzani (spoon handling) and Aroosakgardani (puppet handling). Aestheticism relying on traditional performing method is also the outcome of taste and elegance of common people. These performances have more folkloric aspects protruding from humane institutions and blended with their vernacular beliefs. In the traditional method of performance art, performers mostly enjoy their own taste and style and use handy means for executing their roles. In contemporary Iran, traditional method along with modern theme has been widespread among people particularly in villages and small townships although these are not called as art. The present study is an attempt to study existing challenges to modern and ancient art traditions as well as aesthetic values attributed to each of them.
\end{abstract}

Keywords: performance art, tradition, modern, conceptual art, formal representation, contemporary Iran, vernacular beliefs, academic

\section{Introduction}

The performance art is the one that with respect to recognition and popularity is more related to post-modernism but from the point of view of concept and execution, it is closer to folkloric or traditional rules and regulation.

The performance art being complex in nature, it incorporates different elements of other arts like painting, sculpture, music, theatre, dance, video film, or a combination of all. All these definitions agree to the point that the performance began in early 1970s and gradually took its present form. However, if we confine ourselves to the exiting definition of performance art, it seems we encounter with an artistic limitation.

In this article, we try to emphasize on the fact that although the performance art, officially and methodically, introduced in 1970s, but its roots date back to religious art and belief of each region. This art has

Parisa Shad Ghazvini, Ph.D., Associate Professor, Painting Department, Art Faculty, Alzahra University. 
had such a functional expansion that it could include arts ranging from dramatic to dance performances. According to the recent definition, the precedence of performance art in Iran goes back to a few centuries that include diverse mentalities and structures.

Performing traditional ceremonies and customs were prevalent in Iran since long time ago, especially among ordinary people. One of the existing indicators of the Iranian art that has continued in present times is the loyalty to tribal memories which always preserve the mental structures and the cultural framework. In this pattern, ancient shapes and visages appear not only in external manifestation and identical symbols rather take rebirth in their own substance. As Titus Burckhardt believes, the power of tradition is creator of traditional civilization style which is impossible to be imitated from elsewhere and will remain steady and continuous by its own spiritual and divine strengths.

\section{History of Performance Art in Iran}

As mentioned, if we do not limit the concept of performance art merely to recent discussions and theories, and if we believe that ceremonies and customs themselves have the concept of performing arts, then it can easily be confirmed that the performance art enjoys a long historical background in Iran. All customary concepts that are outcome of internal social institutions in a way could have reliance upon the performing art. In addition, it can have narrative, epical, literary, and even political beliefs. In Iran, traditional and modern performance arts have some common points both in performing structure and aesthetic sense hence; existing differences cannot be ignored.

Iranian artist has been narrating stories, events and patterns over and over with different forms for centuries. And, it is the figures that change in their narratives but contents remain intact. The spiritual experience of Iranian artists attracts him toward the Unity of Being. The united spirit of the artists absorbs them in reviving the national and religious treasures. One of the most prominent form of religious performance that is rooted in epic rituals and religious ceremonies of Shiite faith is the events of Karbala that describes the martyrdoms of Imam Hussein (grandson of Prophet Mohammad) and his companions. These performances are being executed in the form of Ta'azieh (passion play). Shabihkhani (morality play), Shamayelgardani (icon handling), Naghali (storytelling), and Pardehkhani (curtain play) are other branches detached from traditional performance arts. These arts reveal themselves in the form of religious art and the aim of such representation is to show cruelty toward the family of the prophet. In fact, through the communication with godly men, human beings become closer to god. This performance is the one that is formed along with religious customs and formalities.

\section{Traditional Performance Art in Iran}

In the section, the traditional performance arts are classified and then each being discussed separately. Ru-howzi (performance on pool platform), Marekegiri (mono drama), Qhashoqhzani (spoon handling), and Aroosakgardani (puppet handling) are some of the traditional performance arts in Iran.

\section{Ta'azieh Khani (Quite Singing or Passion Play)}

Ta'azieh is religious epical performance that has an ancient precedence in Iranian art. This performance has a dramatic, religious structure. The root of its organized form goes back to Zand dynasty.

Initially, Ta'aziehkhani or passion play was a simple performance that gradually became complex and mixed with other elements such as mourning recital, characterization, music and narrative texts. Peak of this 
growth and transformation is Rauzehkhani (commemorating Karbala martyrdoms). In Rauzehkhani, the sermonizer not only narrates the events of Karbala rather he performs completely artistic in presenting monologues, dialogues, and musical aspects. Elements like copy of passion that was composed by Mohtesham Kashani could bring evolution. Other feature of the religious art is that audience is considered to be both part and component of the performance. There is no particular place for the performance of the passion play.

\section{Place of Ta'azieh}

A circular place is erected or selected to perform the passion play that is attended by people from all level of a society. Audience assembles around the circular place and they enjoy from the representation alike. In other words, all audience is the same at this place no matter they belong to higher or lower strata. Another important point is the connection between audience and the stage. Throughout the performance, there is a spiritual and sentimental connection between the passion performers and the audience. People attending the passion play often solemnize to god and give alms for good and to ward off evils. Ta'azieh performers do speak to the audience and sit among them. All these criteria make it evident that audience of the passion play is attended at par with performers. There is a big interchange of witness, mind freedom, and great willing in these communities. Apart, the audiences use to teach morality, benevolence, deliberative point, liberal thought, and intention to the whole society.

\section{Shamayel Gardani and Shabih Khani (Icon-handling and Morality Play)}

Icon-handling is yet another religious art performance that simulates the life and behaviors of prophets, imams, and godly men. In this art, divine men are represented with hidden faced performer. In fact, the divine men are identified by their good deeds and intentions rather than their complexion hence; the face of a performer must be hidden. The icon handling is more like morality play.

Like other Iranian arts, Shabih Khani or morality play is based on the past traditions and arrangements. This art is rooted in the religious thoughts. It was started in the 4th Century with the command of Moez al-Dauleh Deilami. Since then, it is being performed every year throughout Iran. Like others, its theme, too, is martyrdom of Imam Hussein and his companions in the battle with Yazid's army. Structurally, this particular art is more influenced by other performances such as dirge, martyrdom commemoration, simulation, icon-handling, group-handling, and minstrelsy.

The theme of icon-handling, morality play and even the passion play is the oppositeness of two forces of good and bad, good and evil, benevolence and wickedness and light and darkness. That is why these performing arts are called as "religious art”. These performances have constant plan of a particular religious art.

In the traditional art performances, religious beliefs and social realities are amalgamated hence; lead to complete coordination between aesthetic values and social and philosophical outlook. These performances have attracted the attention of western and oriental researchers. As such, Sir Lewis Pelly (1825-1892) writes about is as:

If the success of a representation is the ratio of its effect on readers or spectators, none of the representation has been as successful as the tragedy of Islamic world i.e. tragedy of Hassan and Hussein (grandsons of Prophet Mohammad). (Lewis, 1978)

And Peter G. Chelovski, an orientalist, tells about these performances as: "Characteristically, this art is amalgamation of explicitness and reflection with truthfulness. To make it a unique vernacular art, it does not demarcate a line between eternity and human, rich and poor, extraordinary and ordinary, spectators" (Chelovski, 
1979). Shabih Khani is a traditional art and due to its relation with "reality" has been transformed into a "divine performance".

\section{Ru-howzi (Performance on Pool Platform)}

Ru-howzi is related to the folkloric genre of drama. This is usually performed in the middle of an empty pool inside a building and audience sit around the pool. In the past, courtyard of each Iranian house contained a pool that has wider application. During get-together or festivities, residents could place a big plank and give it a shape of stage so that actor could perform there. With respect to the presence of a comedian and Siyah or Mobarak in Iran, this representation became famous as "Siayah Baazi” or “Takht Howzi” or Ru Howzi”. Today, this art is on the verge of decline in Iran.

The theme of this performance is very simple often representing peoples' lives such sentimental relationship between families or a love affair between a boy with the neighbor's daughter and problems arising out of it. In this drama, a character named Mobarak who is the symbol of servant is always present on the stage with red costume and blackened face. This person is manifestation of an ordinary man from lower rung who makes fun of the entire story by dancing, like the one we see in "American-African black culture". His movement is usually folkloric and undistinguished. With his performance, Mobarak tries to present socio-cultural criticism.

\section{Marekegiri (Mono Drama)}

Marekegiri is a popular art usually played by one performer. In this art, Marekegir amuses his audiences through strange performances. In Iran, they played some extraordinary performances such as tearing apart of shekels, breaking stone with hand or head or playing with venomous serpent. In this art, the performer makes some fast and active movements and talks with his specific rhythmic words. The performer usually makes noise or claps to attract and entertain the audiences.

One of the most favorable mono dramas is "snake charming". Performers often ended his representation by showing some big and small snakes or tearing apart chains. Marekegiri is always performed free of cost but audience voluntarily paid the performers some amount as gift. This art is almost ruined in the contemporary Iran and could rarely find in some remote places.

\section{Ghashoghzani (Spoon Handling)}

This performance is a popular tradition among Iranians and used to perform on the last Wednesday of the Iranian calendar (i.e. Chahar Shambe Suri night). On this day, people try to throw away all kinds of wickedness, foul play, purulence, sourness and replace them with friendships, compassion, and acquaintances. At that time, a number symbolic performance is played and Ghashoghzani or spoon handling is one of them. This art is usually performed at sunset or late night. Young women and men hide their face and go to the doors of others, playing spoon on metal pot and requesting kindness and charity from the housekeepers. They stayed behind the doors to the extent that the housekeepers offer some eatables like nuts, soup, or others. Receiving something is considered as the sign of prosperity for spoon players. Often, these young girls and boys used to visit the doors of their beloved and remain there until they see their beloved.

An Iranian anthropologist, Jehanpour describes the tradition of Ghashoghzani as follows:

In some of the localities, traditionally girls or women who had exigency, used to cover their faces and visited at least seven houses believing that if anyone put things in their bowl, they will attain their exigency. By the same reason, housekeeper could not turn back anyone visiting the house... perhaps the root of spoon handling tradition can be 
considered as the arrival of foroohar (spirits) that some believe come to the earth during the last five days of the year. Foroohar are souls of our ancestors and people believe that they are allowed to revisit this world for a short period and stay along their families on the New Year Eve.

Since these spirits lack bodily essence, spoon players with their hidden faces become symbols and since housekeepers are waiting for their own ancestral spirits, they visualize these spoon players as holy spirits and hence; do not turn them back empty handed. Morally, this tradition is a kind of benevolence and help because most often spoon players are needy persons and due to shyness and humiliation, cover their face and go to peoples' homes. Housekeepers, too, with intension and desire put sweets and nuts and make them partners in his own festivities. (Jehanpour, 2011)

The tradition of Qashoghzani, more or less, is similar to the Halloween tradition prevalent in the Christian world.

\section{Aroosak Gardani (Puppet Handling)}

Puppet-handling is yet another traditional Iranian performance in which; doll or puppet is the main character with director telling an offhand story by handling them. The dolls are made of fabrics that are hanged by some threads. Among these dolls, there is a little Mobarak with typical voice, black face, and red clothes and the director is the only person who realizes him and responds his words to the audiences. This doll is the symbol of little slave who, like Mobarak of Ru-howzi, ridicules and criticizes the rich people.

\section{General Characteristics of Traditional Iranian Performance Arts}

Taking into account the above discussion, the characteristics of the traditional performance arts in Iran can be summarized as below:

(1) The traditional art, in their shape and theme, is customary and religious;

(2) The traditional performance art is immortal and sacred because its essence is fixed and stable;

(3) In the traditional performance art, the artist works for the stability of the artistic traditions that shows his capabilities in preserving these traditions in order to reach to the reality;

(4) In the traditional performance art, individuality of the artist is not shown from his work rather he is a part of the whole collection;

(5) In the traditional performance, the artistic work is considered as a kind of prayer where the artist performs in order to God's favor hence; the traditional art performance has deep attachment with religious rituals;

(6) The traditional performance is a functional art. With its meaningful message, it has mysterious presence and during presentation, it makes audience and performers partners;

(7) Neither time nor place is the real entity in the traditional performance arts;

(8) Aestheticism of traditional arts is based on folkloric beliefs and is affected by the peoples' knowledge and their customary rules;

(9) These arts are governed by some non-standard and subjective rules of improvisation;

(10) In the traditional performance art, the battle between good and evil is considered an important principle that makes it dynamic.

\section{Performance Arts in Contemporary Iran}

This section deals as how performance art, in its theme and method, has been extended during the contemporary Iranian society. With vanishing limitations, arts such as conceptual art, environmental art, 
installation art, and street art have helped the performance art and give multidimensional meaning. Presently, this art is trying to propagate itself among people by focusing on mythological, socio-cultural, political, and environmental subjects. The modern performance arts have distanced so some extent from vernacular and superstitious beliefs as well as topics of everyday life.

In the contemporary performance arts, elements like light and darkness, sound and silence, movement and perseverance, color, music etc. are the tools that carry the concepts and help performers in communicating their messages. Likewise, space and instruments, apart from aesthetic, carry semeiological essence. Application of symbols and visual images are other means for communicating messages.

The modern performance art provides the artists opportunities to present their performance seriously and academically before the audience. Following are some successful performance arts in Iran.

\section{Performance Art Project in Village}

The village art project that was instituted during the last few years is a one-day performance by a group of academic artists. They go to a particular rural area and with the help of local people show their artistic endeavor. They perform an undistinguished and unplanned project in which; the process of execution is important not the final product. As Allan Kaprow (1927-2006) says, the importance of artistic work is seen in the tools, materials, and the stages of production not the remaining objective product and this is exactly a part of the contemporary art which connects the faith to religion.

Another important point related to the "village art project", is the work that was not supposed to be created or happened. A movement itself gives different form in this project that had not planned before, for instance, masks, paintings, and letters that were hanged on a tree. This objectivity and self-boiling, too, are not of the customary elements. Whenever, a distinguished custom is being performed, reciprocal traditions and customs too are included and added in different regions.

Normally, there is a direct connection between artist and audience. In other words, artists create a work with distinct content and message and the audience, on the other hand, receive those contents or messages. For instance, a simple linear graph that begins with an artist and ends with the audience. But as we know, these concepts have been transformed in the contemporary art and audience itself becomes creator and performer of an art. In the aforementioned project, spectators and are also the performers and they are present in all stages and steps. As according to Marcel Duchamp (1887-1968), it is the audience that completes the work of art. Realizing Duchamp's notion, the randomness of events was the integration of audience into the performances.

The village art project aims to reach to the target i.e., the course is considered as an artistic endeavor. This group travel from one to another village and repeat their performances. Villages are invited to see their performances. For instance, the performance is about a museum and audiences enter a gallery and observe a performance.

Audiences that are present on the spot, no matter they did something, the project has achieved its goal. By this way, the thing rural folk comes across is like customary honor. It is not important how much the person believes, but the collective unconscious, traditions and archetypes affect the society.

\section{Performance of "Jonah Fishes"}

One of the environmental arts, Fereshteh Alam Shah has presented her recent work entitled Jonah Fishes, with the participation of 21 people at Gavkhuni pond in the city of Varzaneh. She intended to perform this art between "Si-o-SehPul" and "Pul-e-Khajoo" the two historical bridges in the city of Isfahan, but due to some 
reason, she took her performance at Gavkhuni pond that was dried. Fereshteh Alam Shah executed her work with the belief that "if we behave cruelly with the nature, consequently, our destiny becomes bitter as well".

This work emphasizes upon an environmental disaster being faced by Gavkhuni pond. Today's discussion about Gavkhuni pond needs much attention to others and drying up of Zayendeh Rud in Isfahan has become apprehension of artists. Pointing to the participants in this project, Alam Shah in her interview says each person in this work is represented as a symbol of fish, who by wrapping himself in plastic covers represent the captivity of these creatures. These performers together form a big that too is symbolically dead. Jonah Fishes is allegory to the Prophet Jonah who was captivated in the stomach of a fish due to his disobedience to God.

Today, we witness same disobedience to the nature hence; we are encountering wit the same captivity. The death of nature will certainly lead to the death of human being. With the execution of the aforementioned art, Alam Shah has already projected her environmental art and her emphasis is on Eco Art because she believes that the nature has been the victim with many respects.

\section{Performance of "Merajnameh"}

Beautiful environment and hills of the Island of Hormuz sketch the image of heavens. A new group with the cooperation of Department of Education, along with 70 female students performed in the Island of Hormuz the scene of Merajnameh, 10th century work written by Sultan Mohammed in Tabriz. These young girls with beautiful local costumes were depicted as angels.

\section{Conclusion}

As we know, aestheticism is an essence of artistic works that can be seen in every time, place, period, culture, and belief. There are some common aesthetic principles between traditional and contemporary Iranian arts. One of the most obvious aspects of aestheticism in the traditional and modern modes is the conflict between good and evil, darkness and light, to be and not to be.

In a nutshell, following conclusion can be extracted from the above discussion:

(1) The performance art in Iran, with a precedence of few centuries, includes all customary performances;

(2) All kinds of traditional and modern performance arts have had much impact on the society;

(3) Both traditional and modern performance arts in Iran have common roots and structurally they enjoy great unity;

(4) Both traditional and modern performance arts in Iran have direct connection in meaning and concept and they are not exaggerator or senseless. Undoubtedly, they point to social, religious, political, economic, or moral aspects;

(5) The traditional performance art in Iran had a popular structure with direct expression, whereas the new performances have intellectual leanings in their contents;

(6) The new mass media like audio-visual media have much impact on new performance arts compare to the past;

(7) Application of sign, symbol, code, dramatic movements, customary movement, sound, and music in the traditional performance art is much closer to the new arts;

(8) Iranian performance artists are neither interested in fame nor to express their individuality rather what they prefer is content, effect, and attraction of audience.

\footnotetext{
${ }^{1}$ It is from her interview.
} 


\section{References}

Baktash, M. (1979). Ta'ziyeh and its Philosophy. In P. J. Chelkowski (Ed.), Ta’ziyeh: Ritual and drama in Iran. New York: New York University Press. Tehran: Soroush Press.

Beiza'i, B. (2000). A study of Iranian theatre. Tehran: Roshangaran and Women's Studies Publishing.

Chelkowski, P. (1979). Tazieh: Indigenous avant-garde theatre of Iran. New York: New York University Press.

Jahanpoor, F. (2011). Interview. Retrieved from https://www.jahannews.com/getiyyarwt1ayp2.cbct.html

Lucie-Smith, E. (2002). Art tomorrow. Paris: Terrial.

Morgan, R. C. (2008). Art in the landscape, An Iranian sculptor brings his art to the river, beaches—and parks. Marked in stone and sand, landscape architecture. The magazine of the American Society of Landscape Architecture, 6.

Sir Lewis, P. (1978). Report on a journey to Riyadh in Central Arabia. Cambridge, Eng.; New York: Oleander.

Mottahedeh, N. (Summer 1999). Resurrection, return, reform: Ta’ziyeh as model for early Babi historiography. Iranian Studies, (32), 3. 